\title{
ISO-PIESTIC SOLUTIONS.
}

\author{
By W. R. BOUSFIELD, K.C., F.R.S.
}

\section{(A Paper read before the Faraday Society, Wednesday, December I2, I9I7.)}

It was natural that in the development of the broad general outlines of the dissociation theory by Arrhenius and others the smaller discrepancies between theory and experiment should be passed over and their consideration postponed. Now, however, that the source of these discrepancies, in the case of aqueous solutions, has in many cases been traced to the composite character of the solvent water, to the changes which take place in its constitution in the presence of a solute, and th the combinations between solvent and solute which usually occur, the study of these discrepancies promises to be fruitful.

As an example of the generalizations which can only be regarded as first approximations, one may refer to the statement of Nernst that "Iso-osmotic solutions contain the same number of molecules of dissolved substance in a given volume at a given temperature, and the number is the same as in an equal volume of a perfect gas at the same temperature and pressure."

Arrhenius and others speak of two solutions which are in osmotic equilibrium with one another as being iso-osmotic or iso-tonic, and come to the conclusion that solutions containing equivalent or equimolecular quantities per litre are iso-osmotic. Arrhenius further describes solutions which do not change their dissociation on mixing as iso-hydric, and describes iso-hydric solutions as containing the same number of gram-ions per litre.

So far as the terms iso-tonic, iso-osmotic, and iso-hydric merely express physical facts, they may be used with accuracy, but it is now recognized that the propositions involving molecular proportions per litre which they are used to connote as above are only first approximations, and they cease to be even approximate when applied to more concentrated solutions. In various papers I have endeavoured to correlate the various osmotic data with the number $h$ of molecules of water per mol of solute, and to deduce the number $n$ of molecules of water combined with a mol of solute.* With the object of deducing these numbers from vapour pressures, I began in I9I3 a series of measurements of vapour pressures which are still incomplete, but as the completion of the work may be long delayed, it seems desirable to indicate the general character of the method and its results in this brief paper.

* See a paper of mine contributed to the recent discussion on Osmotic Pressure, Trans. Farad. Soc., 13, October I917, and the former papers to which reference is there made. 
The method of experiment was determined upon after a number of trials of very various methods and apparatus, to which it is not now necessary to refer. Briefly, the method finally adopted consisted in placing the salts or solutions to be observed in separate open vessels in a common receptacle, which was evacuated to facilitate the exchange of vapour between the solutions in an aqueous atmosphere common to them all, maintained at a uniform temperature. Under such circumstances equilibrium can only be reached by the several solutions gaining or losing water until they arrive at the same vapour pressure. Solutions under such conditions may be said to become iso-piestic. A special word is desirable to denote solutions of equal vapour pressure, since the words iso-tonic, iso-hydric, and iso-osmotic have come to connote theoretical considerations, and are sometimes used inaccurately, whilst the word iso-piestic simply expresses $a$ fact, viz. the equality of vapour pressure of the solutions. Iso-piestic solutions must be, of course, strictly iso-osmotic, since it is the equality of vapour pressure which determines osmotic equilibrium.

The purpose of the main investigation was to determine the relative degrees of hydration of iso-piestic solutions of different salts. Thus, for instance, it was found that for solutions of the following salts, after their solutions had stood in the same aqueous atmosphere for several days at a temperature of $18^{\circ} \mathrm{C}$. to arrive at final equilibrium, the values of $h$ were

$$
\begin{array}{lll}
\mathrm{KCl} . & \mathrm{NaCl} & \mathrm{LiCl} . \\
h=\mathrm{r} 2 \cdot 43 & \mathrm{I} 4 \cdot 23 & \mathrm{I} 7 \cdot 18
\end{array}
$$

Such solutions are therefore iso-piestic at $18^{\circ} \mathrm{C}$.

Some hundreds of experiments were made, covering the range from concentrated to dilute solutions, but owing to certain difficulties of manipulation the general results have not yet been completed. But from the experiments selected valuable deductions can be drawn, which will serve to indicate the capabilities of the method.

Four cylindrical glasses of about $5 \mathrm{~cm}$. diameter and $4 \mathrm{~cm}$. deep were arranged on a tin stand, by means of which they could be easily lifted into and out of a Hempel desiccator. Each glass was furnished with a loose ground cover and a piece of platinum for occasional stirring. The lid of the Hempel desiccator was well ground so as to make a good joint with the body, the joint being luted with vaseline. The lid was also furnished with a well-ground tap. The trough of the lid was used to contain a little water or drying substance, as required.

Four pure salts were taken, viz. $\mathrm{KCl}, \mathrm{NaCl}, \mathrm{LiCl}$, and $\mathrm{KNO}_{3}$ (in weights of 2 to 3 grams), dried and placed hot in the glasses, with stirrers and covers previously weighed, cooled in the evacuated desiccator and weighed. The first three had been melted into beads on platinum. The glasses were then arranged on the stand and placed in the desiccator, the covers removed, the desiccator closed, with a little water in the trough, and evacuated by means of a good filter pump, capable of reducing the pressure to about that of the water vapour. The external tube of the tap was then closed by means of a rubber tube and stopper and the desiccator immersed in a large water-bath kept at a regulated temperature of about $18^{\circ}$ and constantly stirred. After an interval of one to three days, the desiccator was taken out of the bath and opened, the covers replaced on the glasses, and each glass weighed to ascertain the amount of water taken up by the salt. A little more water was now placed in the trough and the process repeated. 

Table I.

The results of the earlier stages of an experiment are given in TABLE I.

Successive Values of hat $18^{\prime} \mathrm{C}$.

\begin{tabular}{|c|c|c|c|c|}
\hline & $\mathrm{KCl}$. & $\mathrm{NaCl}$. & LiCl. & $\mathrm{KNO}_{3}$. \\
\hline 1913 & & & & \\
\hline Nov. 12 & o & o & $8 \cdot 02$ & o \\
\hline I5 & o & 0 & $8 \cdot 55$ & o \\
\hline I7 & o & o & $9 \cdot 34$ & o \\
\hline I9 & o & o & $9 \cdot 82$ & 0 \\
\hline $2 \mathrm{I}$ & o & o & $10 \cdot 33$ & o \\
\hline 23 & o & o & 10.79 & o \\
\hline 25 & o & 0.005 & I I $\cdot 24$ & o \\
\hline 28 & o & $0 \cdot 297$ & II $\cdot 45$ & 0 \\
\hline Dec. I & o & $I \cdot I 0$ & I I 59 & o \\
\hline 5 & o & $1 \cdot 86$ & II $\cdot 40$ & $o$ \\
\hline 7 & o & $2 \cdot 09$ & II $\cdot 37$ & o \\
\hline 12 & o & $5 \cdot 37$ & II $\cdot 34$ & o \\
\hline 16 & 0 & $7 \cdot 68$ & II $\cdot 4 I$ & 0 \\
\hline 20 & o & $8 \cdot 2 I$ & II'39 & 0 \\
\hline 25 & 0 & $8 \cdot 86$ & $\mathrm{II} \cdot 42$ & 0 \\
\hline 26 & 0 & $8 \cdot 98$ & II. $4 \mathrm{I}$ & o \\
\hline 28 & o & $9 \cdot 08$ & $11 \cdot 4 \mathrm{I}$ & o \\
\hline 30 & o & 9.08 & $\mathrm{II} \cdot 4 \mathrm{O}$ & 0 \\
\hline
\end{tabular}

The vapour pressures at each stage can be ascertained from those of the $\mathrm{LiCl}$ solutions, which furnish a convenient scale of pressures. It will be observed that up to November 23 rd the vapour pressure is being continually increased by drops of water added, sometimes in the trough and sometimes to the $\mathrm{LiCl}$ solution, but none of the other salts takes up any water from the aqueous vapour in the desiccator.

On November $25^{\text {th the }}$ attack of the water on the $\mathrm{NaCl}$ has begun, and after this date it proceeds rapidly, the vapour pressure from November 28th to December 3oth remaining practically constant and equal to that of a saturated solution of $\mathrm{NaCl}$. The concentration of the $\mathrm{LiCl}$ varies between $h=\mathbf{I} \cdot 59$ and $\mathrm{II} \cdot 37$, but this is due to equilibrium conditions not being always established at the time of weighing. On December 28th all the $\mathrm{NaCl}$ crystals were dissolved, and we therefore have $h=9.08$ for a saturated solution of $\mathrm{NaCl}$ corresponding to a vapour pressure given by the $h=\mathrm{II} \cdot 4^{\circ} \mathrm{LiCl}$ solution.

Strictly speaking, the observation of November 25th leaves open the possibility of there being a solid hydrate of $\mathrm{NaCl}$ with a lower vapour pressure corresponding to $h=\mathrm{II} \cdot 24$ for $\mathrm{LiCl}$. But $\frac{1}{2}$ per cent. of water with $\mathrm{NaCl}$ corresponds to a hydrate composed of $60 \mathrm{mols} \mathrm{NaCl}$ to I mol of water, and the existence of such a hydrate is unlikely. The existence of a trace of hygroscopic impurity is the more probable explanation. 
Another series of experiments gave the critical point at which $\mathrm{NaCl}$ begins to take up water as the vapour pressure corresponding to

$$
\begin{array}{rl}
\mathrm{NaCl} . & \mathrm{LiCl} . \\
h=9 \cdot \mathrm{I} 8 & \mathrm{II} \cdot 49
\end{array}
$$

This was in March 19I4, when the thermo-regulator was probably running at a slightly higher temperature than in December I9r3.

Table II takes up the same series from the point reached on December 28th, when the $\mathrm{NaCl}$ had just all dissolved and formed a solution saturated at $18^{\circ}$.

TABLE II.

\begin{tabular}{|c|c|c|c|c|}
\hline & $\mathrm{KCl}$. & $\mathrm{NaCl}$ & LiCl. & $\mathrm{KNO}_{3}$. \\
\hline $\begin{array}{c}\text { I9I3 } \\
\text { Dec. } 30\end{array}$ & o & $9 \cdot 08$ & $\mathrm{II} \cdot 4 \mathrm{O}$ & o \\
\hline $3 I$ & o & $10.7 \mathrm{I}$ & 13.05 & o \\
\hline 1914 & & & & \\
\hline $\operatorname{Tan} .2$ & o & $12 \cdot 18$ & $\mathrm{I}_{4} .67$ & o \\
\hline 3 & traces & 13.54 & $16 \cdot 12$ & o \\
\hline 5 & $0 \cdot 3^{8}$ & $I_{4} \cdot 5^{2}$ & $\mathrm{I} 7 \cdot \mathrm{I} 7$ & o \\
\hline 6 & $3 \cdot 21$ & 14.41 & $17 \cdot 36$ & o \\
\hline 7 & $5 \cdot 20$ & $14 \cdot 29$ & $17 \cdot 26$ & o \\
\hline 8 & $7 \cdot 66$ & I 4.25 & $17 \cdot 20$ & o \\
\hline IO & $9 \cdot 6 I$ & $\mathrm{I}_{4} \cdot \mathrm{I}_{7}$ & 17.08 & o \\
\hline I I & $10 \cdot 02$ & $14 \cdot 14$ & $16 \cdot 97$ & o \\
\hline I 2 & $10 \cdot 22$ & 1 3.99 & 16.82 & o \\
\hline 13 & IO. 54 & 14.07 & 16.89 & o \\
\hline$I_{4}$ & $10 \cdot 90$ & $14 \cdot 21$ & 16.92 & o \\
\hline I6 & II $\cdot 27$ & $I_{4} \cdot I_{5}$ & $16 \cdot 98$ & o \\
\hline 17 & $\mathrm{II} \cdot 5 \mathrm{I}$ & I $4 \cdot 15$ & 17.07 & o \\
\hline 18 & II $\cdot 73$ & $1_{4} \cdot 1_{4}$ & $17 \cdot 05$ & o \\
\hline 20 & II $1 \cdot 96$ & $14 \cdot 10$ & $1 \% \cdot 00$ & o \\
\hline 25 & $12 \cdot 02$ & $\mathrm{I}_{\mathcal{4}} \cdot 06$ & 16.94 & 0 \\
\hline 26 & $12 \cdot 16$ & 14.07 & 16.95 & o \\
\hline 28 & I $2 \cdot 26$ & $\mathrm{I}_{4} \cdot \mathrm{O}_{5}$ & 16.92 & o \\
\hline $3 I$ & $12 \cdot 43$ & $14 \cdot$ I I & $16 \cdot 98$ & o \\
\hline Feb. 2 & $12 \cdot 4 \mathrm{O}$ & I $4 \cdot$ I I & $16 \cdot 99$ & o \\
\hline 4 & $12 \cdot 39$ & $\mathrm{I}_{4} \cdot \mathrm{I}$ I & $16 \cdot 98$ & o \\
\hline
\end{tabular}

Successive Values of $\mathrm{h}$ at $18^{\circ}$ (continued).

It will be observed that the $\mathrm{KCl}$ and $\mathrm{KNO}_{3}$ remained substantially unattacked by water until January $5,19 r_{4}$, from which point, until

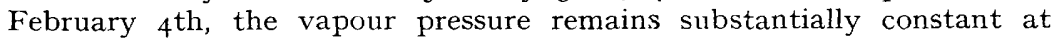
the pressure of saturated $\mathrm{KCl}$, which is probably slightly lower than that which corresponds to the last stage. Here, again, the first attack of the water on the $\mathrm{KCl}$ on January $3 \mathrm{rd}$ is at a pressure slightly lower than the vapour pressure of saturated $\mathrm{KCl}$, possibly owing to traces of a hygroscopic impurity. 
Another series which arrived at equilibrium with saturated $\mathrm{KCl}$ in April ror4 gave the following final values:

$$
\begin{array}{ccc}
\mathrm{KCl} . & \mathrm{NaCl} & \mathrm{LiCl} . \\
h=\mathrm{I} 2 \cdot 43 & \mathrm{I} 4 \cdot 22 & \mathrm{I} 7 \cdot \mathrm{I} 6
\end{array}
$$

Hitherto there has been no attack on the $\mathrm{KNO}_{3}$. Table III takes up the same series from the point where the $\mathrm{KCl}$ has dissolved in saturated solution on February $4^{\text {th. }}$

TABLE III.

\begin{tabular}{|c|c|c|c|c|}
\hline & $\mathrm{KCl}$. & $\mathrm{NaCl}$ & $\mathrm{LiCl}$ & $\mathrm{KNO}_{3}$ \\
\hline I9I4 & & & & \\
\hline Feb. 4 & I $2 \cdot 39$ & $\mathrm{I}_{4} \cdot \mathrm{II}_{\mathrm{I}}$ & I6.98 & 0 \\
\hline 6 & $12 \cdot 4^{6}$ & $\mathrm{I} 4 \cdot \mathrm{I} 8$ & $17 \cdot 04$ & o \\
\hline 8 & 12.47 & $14 \cdot 19$ & I $7 \cdot 07$ & o \\
\hline I0 & I $2 \cdot 4^{8}$ & $\mathrm{I}_{4} \cdot 2 \mathrm{O}$ & $17 \cdot 08$ & o \\
\hline I 3 & I $2 \cdot 76$ & 14.47 & $17 \cdot 34$ & o \\
\hline 15 & I 3.36 & $\mathrm{I}_{5} .02$ & I $7 \cdot 84$ & o \\
\hline 17 & 13.57 & I 5.29 & $18 \cdot 19$ & o \\
\hline 18 & I 4. I I & 15.86 & I $8.9 I$ & o \\
\hline 20 & 14.75 & 16.47 & 19.46 & o \\
\hline $2 \mathrm{I}$ & 15.68 & $17 \cdot 35$ & $20 \cdot 37$ & o \\
\hline 22 & I $6 \cdot 57$ & $18 \cdot 20$ & $2 I \cdot 22$ & o \\
\hline 24 & $17 \cdot 18$ & I 8.89 & $22 \cdot 06$ & trace \\
\hline
\end{tabular}

Successive Values of $\mathrm{h}$ at $18^{\circ}$ (continued).

Unfortunately, the series came to an end on February $24^{\text {th }}$, owing to the accidental spilling of a drop of solution. The figures of that date may, however, be taken approximately as giving the point at which dry $\mathrm{KNO}_{3}$ begins to be attacked, for the following reason. The series

TABLE IV.

\begin{tabular}{|c|c|c|c|c|}
\hline & $\mathrm{KCl}$. & $\mathrm{NaCl}$. & $\mathrm{LiCl}$. & $\mathrm{KNO}_{3}$ \\
\hline I9I3 & & & & \\
\hline Nov. 4 & I $3 \cdot 18$ & 16.09 & I $7 \cdot 46$ & $7 \cdot 26$ \\
\hline 5 & $I_{4} \cdot 63$ & $17 \cdot 23$ & I 8.87 & 3.76 \\
\hline 7 & 15.66 & 18.06 & $20 \cdot 13$ & 0.93 \\
\hline
\end{tabular}

Successive Values of $\mathrm{h}$ at $18^{\circ} \mathrm{C}$.

of figures given in Table IV was obtained by the reverse process. The weighed salts were first allowed to absorb water and then to come to equilibrium among themselves. The $\mathrm{KNO}_{3}$ solution was a saturated solution containing undissolved crystals. 
These figures do not represent accurate equilibrium figures, as the process of vapour transfer has not come to an end. But they are interesting as showing the reverse process of the drying of the $\mathrm{KNO}_{3}$ in the presence of the other solutions.

One important result of the whole series is to show that in each case there is a critical hydration pressure below which no attack is made by the water upon a salt.

The vapour pressure of solid salts which crystallize with water of crystallization has been studied by Andreæ, Frowein, Pareau, and others, and the principles relating thereto have been shortly formulated by van't Hoff.* The vapour pressures of the three solid hydrates of copper sulphate furnish one of the most familiar examples. These principles do not appear to have been developed or generally recognized in relation to the solution and drying of anhydrous solid salts. For example, one finds the statement that "pure $\mathrm{NaCl}$ is very slightly hygroscopic, taking up about $\frac{1}{2}$ per cent. of water from moist air."

The deduction to be drawn from the observations above described is that--

For a pure salt (such as $\mathrm{NaCl}$ ), without water of crystallization, there is, at a given temperature, a certain vapour pressure of water, below which the dry salt surrounded by aqueous vapour will not take up water, and will, if it is not dry, become dried. This pressure may be called the criticat hydration pressure of the salt at the given temperature.

If the salt forms a series of solid hydrates, like $\mathrm{CuSO}_{4}$, the critical hydration pressure would be the vapour pressure of the first solid hydrate. If the salt forms no solid hydrates under the given conditions, the critical hydration pressure is the vapour pressure of the saturated solution of the salt. The vapour pressure of the saturated solution is, of course, the equilibrium vapour pressure reached when part of the salt is dry and part in solution.

From the known fact that $\mathrm{CuSO}_{4} \mathrm{H}_{2} \mathrm{O}$ has a definite vapour pressure of $4.4 \mathrm{~mm}$. (at $5^{\circ}$ ), and that the vapour pressure is zero for dry $\mathrm{CuSO}_{4}$, one might infer the critical hydration pressure of $4.4 \mathrm{~mm}$. It is well, however, to place the principle on a broader foundation and to formulate it definitely, as it has an obvious practical application in reference to the drying of salts and the consolidation of the crystals into a compact miass under atmospheric influences.

In order to translate the figures above obtained into vapour pressure expressed in $\mathrm{mm}$. of mercury, we require a scale of vapour pressures. If this can be established for one of the salts, it gives the vapour pressure for the iso-piestic solutions. A means of doing this is given by the osmotic and ionization relations established in a former paper. $t$ It was there shown that the relation

$$
n=38 a-\mathbf{I}_{4}
$$

held approximately for the relation between the ionization $\alpha$ and the number $n$ of combined water molecules in the case of $\mathrm{LiCl}$ solutions at I $8^{\circ}$. A closer working out of the figures gives the relation as

$$
n=36 \cdot 3 a-13 \cdot 22 \text {. }
$$

* Lectures on Theoretical and Physical Chemistry English ed., Part I: p. 56. $\dagger$ Bousfield, Trans. Chem. Soc, I06, I809, I914. $\ddagger$ Loc. cit., p. 1820. 
It was also shown that the dilution law

$$
\frac{\alpha^{2}}{\mathrm{I}-\alpha}=\mathrm{K}(h-n)^{\frac{1}{2}}
$$

was an accurate law, where $\mathrm{K}$ could with considerable accuracy be taken as a constant, although the mass action law theoretically demanded a small amount of variability of $\mathrm{K}$ with the variation of the composition of the free water of the solution. Neglecting this small variation, we can, from the expressions

$$
\begin{aligned}
& n=h-\frac{a^{4}}{\mathrm{~K}^{2}(\mathrm{I}-\boldsymbol{\alpha})^{2}}, \\
& n=36 \cdot 3 \alpha-\mathrm{I} 3 \cdot 22,
\end{aligned}
$$

by taking various values for $\boldsymbol{a}$, make a table of corresponding values of $h$ and $n$, from which the scale of vapour pressures of $\mathrm{LiCl}$ solutions at $\mathrm{I} 8^{\circ}$ may be obtained by means of the relation *

$$
\frac{\delta p}{p}=\frac{\mathrm{I}+\alpha}{h-n},
$$

where $p$ is the vapour pressure of water at $18^{\circ}$ and $i p$ is the vapour

\begin{tabular}{|c|c|c|c|c|}
\hline$a$. & $n$ & $h$. & $i p / p$ & $\begin{array}{l}\text { Difference for } \\
\qquad h=\mathrm{I}\end{array}$ \\
\hline 0.44 & $2 \cdot 75$ & $7 \cdot 00$ & $0 \cdot 3388$ & \\
\hline 0.45 & $3 \cdot 12$ & $7 \cdot 95$ & $0 \cdot 3002$ & $\begin{array}{l}0.0406 \\
0.0333\end{array}$ \\
\hline 0.46 & $3 \cdot 4^{8}$ & $8 \cdot 9.5$ & $0 \cdot 2669$ & $\begin{array}{l}0.0333 \\
0.0271\end{array}$ \\
\hline 0.47 & 3.84 & $10 \cdot 02$ & $0 \cdot 2379$ & $\begin{array}{l}0.027 \mathrm{I} \\
0.0224\end{array}$ \\
\hline $0 \cdot 48$ & $4 \cdot 20$ & $1 I \cdot I 9$ & 0.2117 & $\begin{array}{l}0.0224 \\
0.0180\end{array}$ \\
\hline 0.49 & $4 \cdot 57$ & $12 \cdot 46$ & $\mathrm{O} \cdot \mathrm{I} 888$ & $\begin{array}{l}0.0180 \\
0.0148\end{array}$ \\
\hline 0.50 & 4.93 & $\mathrm{x} 3.83$ & O.I 685 & $\begin{array}{l}0.0148 \\
0.0151\end{array}$ \\
\hline $0.5 \mathrm{I}$ & $5 \cdot 29$ & $15 \cdot 32$ & 0.1505 & $\begin{array}{l}0.0121 \\
0.00075\end{array}$ \\
\hline 0.52 & $5 \cdot 66$ & I $6 \cdot 95$ & $0 \cdot 1346$ & $\begin{array}{l}0.00975 \\
0.00799\end{array}$ \\
\hline 0.53 & $6 \cdot 02$ & $18 \cdot 74$ & 0.1203 & 0.00649 \\
\hline 0.54 & $6 \cdot 38$ & $20 \cdot 68$ & $0 \cdot 1077$ & $\begin{array}{r}0.00526 \\
0.00\end{array}$ \\
\hline 0.55 & $6 \cdot 75$ & $22 \cdot 83$ & 0.09639 & $0.00_{42} 8$ \\
\hline $9 \cdot 5^{6}$ & $7 \cdot \mathrm{II}$ & $25 \cdot 19$ & 0.08628 & 0.00347 \\
\hline 0.57 & $7 \cdot 47$ & $27 \cdot 79$ & $0 \cdot 07726$ & $0.0028 \mathrm{I}$ \\
\hline $0.5^{8}$ & $7 \cdot 83$ & $30 \cdot 67$ & o.069I8 & 0.00226 \\
\hline 0.59 & $8 \cdot 20$ & $33 \cdot 86$ & 0.06196 & 0.00183 \\
\hline 0.60 & $8 \cdot 56$ & $37 \cdot 39$ & $0.0555^{\circ}$ & \\
\hline
\end{tabular}
pressure lowering.

TABLE V.

Values of ip/p for LiCl Solutions at $18^{\circ}$.

The validity of this table rests on Tammann's experimental values $\dagger$ for $\delta p$ for LiCl solutions of four strengths at temperatures between $40^{\circ}$

* Loc. cit., p. I8I8.

$\dagger$ Landolt Bernstein Tables. 
and $100^{\circ}$. From these the figures at $18^{\circ}$ are diagrammatically extrapolated.* These extrapolated values are given in Table VI, together with the values calculated directly from Table V. It will be seen that Table $\mathrm{V}$ gives values completely in accord with Tammann's experimental results. The difficulty of obtaining accurate vapour pressures at the low temperature of $18^{\circ}$ by direct measurement is very great. Tammann's pressures at higher temperatures, which give a range of 25 values between $40^{\circ}$ and $100^{\circ}$ for each concentration, furnish a basis for extrapolation

TABle VI.

LiCl Solutions at $\mathrm{I}^{\circ}$.

\begin{tabular}{l|c|c|c}
\hline$h$. & $\begin{array}{c}i p / p \text { from } \\
\text { Tammann. }\end{array}$ & $\begin{array}{c}i p / p \text { from } \\
\text { Table V. }\end{array}$ & Difference. \\
\hline 7.275 & 0.326 & 0.327 & \\
10.40 & 0.229 & 0.229 & \pm \\
16.25 & 0.140 & 0.141 & \pm \\
29.19 & 0.073 & 0.073 & \pm \\
\hline
\end{tabular}

which probably leads to more accurate results for $18^{\circ}$ than could be obtained by direct measurement. The more accurate and authoritative determination of such a scale for $\mathrm{LiCl}$, by the collaboration of various observers, is greatly to be desired. It would render the determination of the vapour pressure of any solution by comparison with the $\mathrm{LiCl}$ standard by the method above described a simple matter.

With the help of Table $\mathrm{V}$ it is now possible to express the critical hydration pressures for $\mathrm{KCl}$ and $\mathrm{NaCl}$ at $18^{\circ}$ in terms of $\mathrm{mm}$. of mercury with some accuracy. The values of $h$ for $\mathrm{LiCl}$ solutions corresponding to the critical pressures for the other salts are--

$\begin{array}{rrrr} & \mathrm{KCl} & \mathrm{NaCl} & \mathrm{KNO}_{3} . \\ \text { for } \mathrm{LiCl} & h=\mathrm{I}_{4} \cdot 5^{\circ} & \mathrm{IO} \cdot 8 \mathrm{O} & 22 \cdot 0 \mathrm{O}\end{array}$

the value for $\mathrm{KNO}_{3}$ being only an approximate figure. The values of $\delta p / p$ calculated from Table $\mathrm{V}$ are

$$
\begin{aligned}
& \mathrm{KCl} . \quad \mathrm{NaCl} . \quad \mathrm{KNO}_{3} \text {. } \\
& \delta p / p=0.160 \quad 0.220 \quad 0 . \text { IOI }
\end{aligned}
$$

and the corresponding critical vapour pressures at $18^{\circ}$ in $\mathrm{mm}$. of mercury are therefore

$$
\begin{array}{lll}
12.92 & 12 \cdot 00 & 13.83
\end{array}
$$

the vapour pressure of water at $18^{\circ}$ being taken as 15.38 .

We may give a further example of the kind of information which iso-piestic solutions will give us when the basic data for a standard substance are accurately determined. To follow the modus operandi 
in detail it is necessary for the reader to have before him the former paper.*

Our two sets of values for solutions iso-piestic with a saturated solution of $\mathrm{KCl}$ at $\mathrm{I} 8^{\circ}$ are

$\begin{array}{ccc}\mathrm{KCl} . & \mathrm{NaCl} & \mathrm{IiCl} . \\ \mathbf{I 2} \cdot 43 & \mathbf{I} 4 \cdot 22 & \mathbf{I} 7 \cdot \mathbf{I} 6 \\ \mathbf{I} 2 \cdot 39 & \mathrm{I} 4 \cdot \mathbf{I} \mathbf{I} & \mathbf{I} 6.98\end{array}$

The mean values are

$$
\begin{array}{lll}
12 \cdot 41 & 14 \cdot 16 & 17 \cdot 07
\end{array}
$$

From the standard table for $\mathrm{LiCl}$ values we get the value of $\delta p / p$ when $h=\mathrm{I} 7 \cdot 07$ as

$$
i p / p=0 \cdot 1336 .
$$

For the values of the constant $K$ we have

$$
\begin{array}{rrr}
\mathrm{KCl} . & \mathrm{NaCl} & \mathrm{LiCl} . \\
\mathrm{I} / \mathrm{K}=5 \cdot 370 & 5 \cdot 82 \mathrm{I} & 5 \cdot 966
\end{array}
$$

whence we get

$$
\log \frac{\mathrm{K}^{2}}{\delta p / p}=\overline{\mathrm{r}} \cdot 4^{\mathrm{r}} 4^{25} \quad \overline{\mathrm{I}} \cdot 34459 \quad \overline{\mathrm{I}} \cdot 32283 .
$$

Thence for the values of $\alpha$ we get from the table $\dagger$

$$
a=0.5395 \quad 0.5251 \quad 0.5207 .
$$

It would thus appear that the ionization of a saturated $\mathrm{KCl}$ solution is greater than that of the iso-piestic solutions of $\mathrm{NaCl}$ and $\mathrm{LiCl}$, which is probably connected with the fact that there is more free water in a saturated solution of $\mathrm{KCl}$ than there is in the more dilute solutions of the other salts. Since

$$
(h-n) \delta p / p=I+\alpha
$$

we can calculate the free water $h-n$, and we obtain

$$
\begin{array}{rll}
\mathrm{KCl} . & \mathrm{NaCl} & \mathrm{LiCl} . \\
h-n=\mathrm{II} \cdot 5^{2} & \mathrm{II} \cdot 4 \mathrm{I} & \mathrm{II} \cdot 38
\end{array}
$$

from which we get for the combined water

$$
\begin{array}{lll}
n=0.89 & 2 \cdot 75 & 5.69
\end{array}
$$

for these iso-piestic solutions.

It thus appears that for these iso-piestic solutions the amounts of free water are nearly the same, the balance of the water being made up by the differing amounts of combined water, which are roughly one, three, and six molecules respectively for the different salts, when the free water for all is about eleven and a half molecules.

* "Ionization and the Law of Mass Action, Part III," Trans. Chem. Soc., I06, I8II, I9I 4 .

† Loc. cit., p. 1828 .

VOL. XIII-T14 
It is of interest to compare the results for saturated solutions of the three salts at $18^{\circ}$, which are given in the following table, those for $\mathrm{LiCl}$ being taken from the former paper, ${ }^{*}$ and those for $\mathrm{NaCl}$ being calculated from the iso-piestic data in the mode above described for $\mathrm{KCl}$.

TABLE VII.

Comparative Data for Saturated Solutions at $18^{\circ} \mathrm{C}$.

\begin{tabular}{|c|c|c|c|c|c|}
\hline & $h$. & $\delta p / p$ & $\alpha$. & $h-n$. & $n$ \\
\hline $\mathrm{KCl}$ & $12 \cdot 43$ & 0.1336 & 0.540 & $\mathrm{II} \cdot 54$ & 0.89 \\
\hline $\mathrm{NaCl}$ & $9 \cdot 13$ & $0 \cdot 2072$ & 0.486 & $7 \cdot 18$ & I.95 \\
\hline $\mathrm{LiCl}$ & 3.00 & 0.875 & $0 \cdot 400$ & $I \cdot 60$ & I. 4 O \\
\hline
\end{tabular}

The above examples will serve to illustrate the kind of results which may be obtained by the study of iso-piestic solutions. The method appears to admit of a relative accuracy in the determination of vapour pressures of a high order. The accurate determination of the absolute values of vapour pressures of one substance, such as $\mathrm{IiCl}_{2}$ would enable the absolute values of other substances to be readily determined with equal accuracy by the iso-piestic method. 